\title{
Effects of Anaerobiosis and Nitrate on the Expression of Succinate Dehydrogenase and Enzymes Associated with Nitrogen Metabolism in Klebsiella pneumoniae
}

\author{
By ROBERT HANAU† AND RICHARD B. GOLDBERG* \\ Department of Biology, Temple University, Philadelphia, Pennsylvania 19122, U.S.A.
}

(Received 17 September 1981; revised 14 December 1981)

\begin{abstract}
We have shown that the low histidase activity found in anaerobic, nitrogen-limited cultures of Klebsiella pneumoniae is due to repression of the right-hand hut operon. In addition, we have examined the effects of $\mathrm{NO}_{3}^{-}$on the aerobic and anaerobic expression of catabolite- and $\mathrm{NH}_{4}^{+}$-repressible enzymes in this organism. $\mathrm{NO}_{3}^{-}$permitted anaerobic growth of $K$. pneumoniae in minimal medium containing histidine as the sole carbon source, and histidase and succinate dehydrogenase were derepressed during anaerobic growth in histidine $/ \mathrm{NO}_{3}^{-}$ medium. Use of sucrose rather than histidine as the carbon source reversed the effects of $\mathrm{NO}_{3}^{-}$ and repressed histidase and succinate dehydrogenase activities. Anaerobic growth in sucrose $/ \mathrm{NO}_{3}^{-}$medium also uncoupled the expression of urease and glutamine synthetase.
\end{abstract}

\section{INTRODUCTION}

Facultative anaerobes alter their cytochrome systems and metabolic pathways in response to the presence and absence of oxygen (Haddock \& Jones, 1977; Harrison, 1976). Studies by Gray et al. (1966) and Amerishingham \& Davis (1965) have shown that both succinate and $\alpha$-ketoglutarate dehydrogenase activities are lower in anaerobic than in aerobic cultures of Escherichia coli. In the absence of these enzymes the remaining Krebs cycle enzymes function as a non-cyclic, branched pathway. The reductive branch of the pathway converts oxaloacetate to fumarate and the oxidative branch converts citrate to $\alpha$-ketoglutarate.

The studies of Gray et al. (1966) and of Amerishingham \& Davis (1965) also showed that the addition of glucose and other fermentable carbon sources to aerobic cultures mimics the effects of anaerobiosis, and represses succinate and $\alpha$-ketoglutarate dehydrogenase activities. In other studies on the regulation of metabolic pathways by oxygen, Kistler \& Lin (1971) have shown that the addition of $\mathrm{NO}_{3}^{-}$to anaerobic cultures of $E$. coli results in the expression of the aerobic glycerol dissimilatory pathway. Similarly, Dobrogosz (1966) has shown that the addition of $\mathrm{NO}_{3}^{-}$to anaerobic cultures of $E$. coli alters the pattern of glucose fermentation products from that characteristic of anaerobic cultures to a pattern characteristic of aerobic cultures. Lessie \& Neidhardt (1967) have shown that the addition of $\mathrm{NO}_{3}^{-}$to the culture medium permits the obligate respiratory organism Pseudomonas aeruginosa to utilize histidine as a carbon source under anaerobic conditions. Under these conditions $\mathrm{NO}_{3}^{-}$ presumably acts as both the terminal electron acceptor and as a source of nitrogen.

We have previously examined the effects of oxygen deprivation on the expression of several enzymes involved in the nitrogen metabolism of $K$. pneumoniae (Goldberg \& Hanau, 1980). Our studies demonstrated that anaerobic conditions uncouple the regulation of histidase from that of glutamine synthetase and urease. We report here further studies of anaerobiosis in $K$. pneumoniae.

† Present address: Department of Biological Sciences, Purdue University, West Lafayette, Indiana 47907, U.S.A 
Using hut-lac fusions (Casadaban \& Cohen, 1979) we have shown that the low activity of histidase under anaerobic conditions results from repression of transcription from the right-hand hut promoter, hutP. We also have shown that $\mathrm{NO}_{3}^{-}$in the presence of a non-fermentable carbon source such as histidine permits the anaerobic expression of both histidase and succinate dehydrogenase. In the course of these studies it was found that $\mathrm{NO}_{3}^{-}$ apparently uncouples the regulation of urease from that of glutamine synthetase.

\section{METHODS}

Chemicals. All chemicals were reagent grade. Phenazine methosulphate, 2,6-dichlorophenolindophenol, isopropyl $\beta$-D-thiogalactopyranoside, $\quad 5$-bromo-4-chloro-3-indolyl- $\beta$-D-galactopyranoside, $\quad o$-nitrophenyl- $\beta$-Dgalactopyranoside and NADPH were purchased from Sigma. Ampicillin was a gift from Smith, Kline and French. Carbenicillin was a gift from Roerig.

Bacteria and growth conditions. Klebsiella pneumoniae strain KG7035 is a $\mathrm{Lac}^{+} \mathrm{Rha}^{-}$metB hutC derivative of strain KP5022. Both strains have been described previously (Goldberg \& Hanau, 1980). Strain KG7802 hut $H: \operatorname{Mud}\left(\mathrm{Ap}^{r} l a c\right)$ is a derivative of the hutC strain KG7035. LB medium (Prival \& Magasanik, 1971) was used to prepare $\mathrm{Mu}$ lysates and for Mu mutagenesis. All cultures used in physiology experiments were grown at $32{ }^{\circ} \mathrm{C}$ in W medium (Smith et al., 1971) supplemented with the following micronutrients: $\mathrm{B}^{3+}, \mathrm{Mn}^{2+}, \mathrm{Zn}^{2+}$, $\mathrm{Cu}^{2+}, \mathrm{Co}^{2+}, \mathrm{V}^{2+}$ and $\mathrm{I}^{-}$present at $0.3 \mathrm{mM}$. $\mathrm{Fe}^{2+}$ and $\mathrm{Mo}^{2+}$ were present at $0.15 \mathrm{~mm}$ and $0.55 \mathrm{~mm}$, respectively. Sucrose ( $44 \mathrm{~mm}$ ) and histidine ( $32 \mathrm{~mm}, \mathrm{pH} 7.0)$ were used as carbon sources. Histidine ( $32 \mathrm{~mm}, \mathrm{pH} 7.0)$, aspartate $(15 \mathrm{mM}, \mathrm{pH} 7.0)$ and ammonium sulphate $(15 \mathrm{mM})$ were used as nitrogen sources. Nitrate $(12 \mathrm{~mm})$ was used as a nitrogen source and/or a terminal electron acceptor as indicated.

Cultures were grown with vigorous shaking (about $400 \mathrm{rev} . \mathrm{min}^{-1}$ ) in $250 \mathrm{ml}$ side-arm flasks containing $75 \mathrm{ml}$ medium. Anaerobic cultures were maintained under an atmosphere of $\mathrm{Ar} / \mathrm{H}_{2} / \mathrm{CO}_{2}(85: 10: 5$, by vol.) in a Coy anaerobic incubator. Cells were harvested during the mid-exponential phase of growth for all assays.

Assays. Protein was determined by the Lowry method. Histidase (Smith \& Magasanik, 1971), urocanase (Smith \& Magasanik, 1971), $\beta$-galactosidase (Smith et al., 1971), glutamine synthetase (Goldberg \& Hanau, 1979), urease (Friedrich \& Magasanik, 1977) and succinate dehydrogenase (Spencer \& Guest, 1973) were assayed according to previously published procedures.

$M u$ mutagenesis and construction of hut-lac fusions. Modifications of previously published procedures (Bachhuber et al., 1976; Casadaban \& Cohen, 1979) were employed to construct hut-lac fusions in $K$. pneumoniae strain KG7035. F'lacI : : MuhP1 cts62 was introduced into a Mud(lac Apr) lysogen of strain C600 (Cameron et al., 1975) and $\mathrm{Mud}\left(\mathrm{lac}_{\mathrm{Ap}} \mathrm{A}\right)$ lysates with the host range of $\mathrm{P} 1$ were prepared. Cells to be mutagenized were grown to about $5 \times 10^{8}$ cells ml ${ }^{-1}$ in $\mathrm{LB}$ broth and $\mathrm{CaCl}_{2}$ was added to a final concentration of $5 \mathrm{~mm}$. Portions $(0.1 \mathrm{ml})$ of the culture were removed and mixed with $2.5 \mathrm{ml}$ of LBC soft agar (LB plus $0.5 \%$ agar, $5 \mathrm{mM}-\mathrm{CaCl}_{2}, 10 \mathrm{mM}-\mathrm{MgCl}_{2}$ ). The mixtures were poured on to $\mathrm{LBC}$ plates ( $\mathrm{LB}$ plus $1.5 \%$ agar, $5 \mathrm{mM}-\mathrm{CaCl}_{2}$, and $10 \mathrm{mM}-\mathrm{MgCl}_{2}$ ) and allowed to dry for 20-30 min. Separate 0.05 ml drops of fresh Mud( $\mathrm{Ap}^{r}$ lac) lysate were placed on top of the soft agar overlay, allowed to dry, and then incubated overnight at $32{ }^{\circ} \mathrm{C}$. A sterile spatula was used to remove the portion of the soft agar overlay containing the outgrowth of cells treated with the Mud(Ap $\mathrm{r} l a c)$ lysate. The cells were washed twice in saline, resuspended in $5 \mathrm{ml}$ of LB broth containing carbenicillin and ampicillin $\left(250 \mu \mathrm{g} \mathrm{ml}^{-1}\right.$ each) and grown overnight. Three rounds of $\mathrm{D}$-cycloserine selection $\left(100 \mu \mathrm{g} \mathrm{ml} \mathrm{m}^{-1}\right)$ were performed on cells from the outgrowth in LB plus carbenicillin and ampicillin and Hut ${ }^{-}$derivatives were isolated. Mutants were scored for inability to utilize histidine as sole source of carbon and nitrogen. The Hut ${ }^{-}$derivatives were scored subsequently for the expression of $\beta$-galactosidase using sucrose/aspartate/5-bromo-4-chloro3 -indolyl- $\beta$-D-galactopyranoside (X-gal) plates. Initial experiments performed on eight independent insertion mutants demonstrated that $\beta$-galactosidase was regulated by $\mathrm{NH}_{4}^{+}$. One such mutant, strain $\mathrm{KG} 7802$, was chosen for further study. This strain lacked histidase but not urocanase activity indicating that $\operatorname{Mud}\left(\mathrm{Ap}^{\mathrm{r}} l a c\right)$ had been inserted into hutH (Goldberg \& Magasanik, 1975).

\section{RESULTS AND DISCUSSION}

\section{Effect of oxygen on the expression of $\beta$-galactosidase in strain $K G 7802$ hutH::Mud(Apr lac)}

Previous studies have indicated that the expression of the hut (histidine utilization) operons in $K$. pneumoniae are regulated in response to a variety of growth conditions. The formation of histidase, the first enzyme in the histidine utilization pathway, is inducible (Schlesinger et al., 1965), subject to catabolite repression (Neidhardt \& Magasanik, 1957), and to repression 
Table 1. Aerobic and anaerobic enzyme levels in strains KG7035 and KG7802 hutH::Mud( $\left.A p^{r} l a c\right)$

$\begin{array}{cccccc}\text { Strain no. } & \overbrace{\mathrm{O}_{2}}^{\text {Conditions* }} & \mathrm{NH}_{4}^{+} & & \overbrace{\text { Histidase }} & \beta \text {-Galactosidase } \\ \text { KG7035 } & + & - & 270 & <5 \\ & + & + & 25 & <5 \\ & - & - & 20 & <5 \\ \text { KGmol min } & \text { Specific activity } \\ & - & + & <5 & <5 \\ & + & - & <5 & 2500 \\ & + & + & <5 & 450 \\ & - & - & <5 & 250 \\ & - & + & <5 & 70\end{array}$

*All cultures were grown in sucrose/aspartate medium; oxygen and ammonium sulphate were present as indicated.

by $\mathrm{NH}_{4}^{+}$(Prival \& Magasanik, 1971). Recently, we have reported (Goldberg \& Hanau, 1980) that oxygen also was required for the expression of histidase and that the lack of histidase expression under anaerobic conditions could not be attributed to inducer exclusion, an increase in catabolite repression, or the inability to synthesize glutamine synthetase (Prival et al., 1973). In these studies we also showed that anaerobiosis results in neither the production of diffusible inhibitors of histidase nor the inactivation of pre-existing enzyme.

Our results suggested that the effects of oxygen deprivation on the expression of histidase resulted from the lack of hut transcription. However, studies by Givot et al. (1969) showed that dehydroalanine is present at the active site of histidase. The presence of this amino acid requires post-translational modification of histidase. Thus, the possibility that the lack of histidase resulted from an inability to produce the enzymically active form could not be eliminated. In this report we show that the low activity of histidase in anaerobic cultures of $K$. pneumoniae is due to anaerobic repression of hut.

The aerobic and anaerobic $\beta$-galactosidase activities of strain KG7802 shown in Table 1 reflect transcription initiated from the right-hand hut promoter in this hutC hutH-lac fusion strain. The levels of histidase and $\beta$-galactosidase in similar cultures of the parent strain, KG7035, are included in Table 1 for comparison. As shown, in the absence of isopropyl $\beta$-D-thiogalactoside (IPTG), $\beta$-galactosidase activity is undetectable in cultures of strain KG7035. In contrast, cultures of strain KG7802 exhibit $\beta$-galactosidase activity in the absence of isopropyl $\beta$-D-thiogalactoside, and this activity is regulated by both $\mathrm{NH}_{4}^{+}$and oxygen. During aerobic growth of strain $\mathrm{KG} 7802, \beta$-galactosidase levels were 6 -7-fold greater in sucrose/aspartate than in sucrose/aspartate/ $\mathrm{NH}_{4}^{+}$medium. Similarly, during anaerobic growth of strain KG7802, $\beta$-galactosidase levels were 3-4-fold greater in sucrose/aspartate than in sucrose/aspartate/ $\mathrm{NH}_{4}^{+}$medium. The maximum anaerobic $\beta$-galactosidase levels in strain KG7802 were, however, 10-fold lower than in comparable aerobic cultures. The enzyme levels (Table 1) of the parental strain, KG7035, show that the effects of $\mathrm{NH}_{4}^{+}$and oxygen on the expression of $\beta$-galactosidase in strain $\mathrm{KG} 7802$ are similar to the effects of $\mathrm{NH}_{4}^{+}$and oxygen on the expression of histidase in strain $\mathrm{KG} 7035$.

The data in Table 1 thus show that anaerobiosis, under conditions of nitrogen paucity, results in a 10 -fold decrease in the activity of $\beta$-galactosidase transcribed from the right-hand promoter of the hutC hutH-lac fusion strain KG7802. The ratio of aerobic to anaerobic $\beta$-galactosidase activity in this strain clearly resembles the ratio of aerobic to anaerobic histidase activity in the parent strain, KG7035. Conditions of anaerobiosis do not result in modification of $\beta$-galactosidase catalytic activity (Cohn \& Horibata, 1959), and we conclude from this data that the effects of oxygen deprivation on $\beta$-galactosidase expression in strain 
Table 2. Aerobic and anaerobic effects of sucrose and $\mathrm{NO}_{3}^{-}$on enzyme levels in strain $K G 7035$

\begin{tabular}{|c|c|c|c|c|c|}
\hline \multirow[b]{2}{*}{ Culture medium } & \multirow[b]{2}{*}{$\mathrm{O}_{2}$} & \multicolumn{4}{|c|}{ Specific activity* } \\
\hline & & Histidase & $\begin{array}{c}\text { Succinate } \\
\text { dehydrogenase }\end{array}$ & $\begin{array}{l}\text { Glutamine } \\
\text { synthetase }\end{array}$ & Urease \\
\hline $\begin{array}{l}\text { Sucrose } / \mathrm{NH}_{4}^{+} \\
\text {Sucrose } / \mathrm{NH}^{+}\end{array}$ & + & 40 & $\begin{array}{l}13 \\
15\end{array}$ & $\begin{array}{l}180 \\
250\end{array}$ & $\begin{array}{l}50 \\
40\end{array}$ \\
\hline $\begin{array}{l}\text { Sucrose } / \mathrm{NO}_{3}^{-} \\
\text {Sucrose } / \mathrm{NO}_{3}^{-}\end{array}$ & + & $\begin{array}{r}90 \\
5\end{array}$ & $\begin{array}{r}17 \\
8\end{array}$ & $\begin{array}{l}600 \\
200\end{array}$ & $\begin{array}{l}460 \\
450\end{array}$ \\
\hline $\begin{array}{l}\text { Histidine } / \mathrm{NO}_{3}^{-} \\
\text {Histidine } / \mathrm{NO}_{3}^{-} \\
\text {Histidine }\end{array}$ & $\begin{array}{l}+ \\
- \\
+\end{array}$ & $\begin{array}{l}301 \\
174 \\
504\end{array}$ & $\begin{array}{r}160 \\
50 \\
68\end{array}$ & $\begin{array}{l}20 \\
90 \\
29\end{array}$ & $\begin{array}{l}<20 \\
<20 \\
<20\end{array}$ \\
\hline
\end{tabular}

* Activities are expressed in nmol product $\min ^{-1}$ (mg protein) $)^{-1}$ except for succinate dehydrogenase activities which are in $\mu$ mol product $\min ^{-1}$ (mg protein $)^{-1}$.

KG7802 and, therefore, on histidase expression in strain KG7035, must be exerted at the level of transcription.

\section{Effects of $\mathrm{NO}_{3}^{-}$on the anaerobic activity of histidase and succinate dehydrogenase}

Growth on histidine, in the absence of another source of carbon, is dependent upon terminal respiration and requires the function of the Krebs cycle. The results of Dobrogosz (1966), Lessie \& Neidhardt (1967) and Kistler \& Lin (1971) suggest that the presence of $\mathrm{NO}_{3}^{-}$in anaerobic cultures mimics the effects of aerobiosis. We therefore examined the ability of $K$. pneumoniae to produce histidase anaerobically in medium containing $\mathrm{NO}_{3}^{-}$. In these experiments the activity of the tricarboxylic acid cycle was monitored by measurements of succinate dehydrogenase activity. This enzyme was chosen because it is the only membrane-bound component of the cycle and its activity provides an indication of both the oxidative function of the cycle and its role in energy production.

First, it was found that although $K$. pneumoniae was unable to grow anaerobically in medium containing histidine as sole source of carbon and nitrogen, the addition of $\mathrm{NO}_{3}^{-}$to histidine medium permitted growth and the expression of histidase and succinate dehydrogenase. As shown in Table 2, succinate dehydrogenase activity was highest in aerobic histidine $/ \mathrm{NO}_{3}^{-}$cultures, but was expressed anaerobically in the presence of $\mathrm{NO}_{3}^{-}$at levels comparable to those found in aerobic histidine cultures. These results suggest that the tricarboxylic acid cycle functions as a complete cycle anaerobically in the presence of $\mathrm{NO}_{3}^{-}$. Histidase activity, although lower in anaerobic histidine/ $\mathrm{NO}_{3}^{-}$cultures than in either aerobic histidine or histidine/ $\mathrm{NO}_{3}^{-}$cultures, was 8-10 times higher than that found previously in sucrose-containing cultures (Goldberg \& Hanau, 1980).

As shown in Table 2, the use of sucrose rather than histidine as a carbon source in medium containing $\mathrm{NO}_{3}^{-}$abolished the anaerobic derepression of succinate dehydrogenase and histidase. The anaerobic levels of these enzymes in sucrose $/ \mathrm{NO}_{3}^{-}$cultures were comparable to, but lower than, the levels detected in anaerobic sucrose/ $\mathrm{NH}_{4}^{+}$medium. Glutamine synthetase levels were comparable in anaerobic sucrose $/ \mathrm{NO}_{3}^{-}$and sucrose $/ \mathrm{NH}_{4}^{+}$cultures and suggested that neither growth medium was 'nitrogen-limited'. Glutamine synthetase levels were lower in aerobic sucrose $/ \mathrm{NO}_{3}^{-}$cultures $\left[600 \mathrm{EU}(\mathrm{mg} \text { protein })^{-1}\right]$ than those found in aerobic sucrose/histidine [1200 EU (mg protein $\left.)^{-1}\right]$ or sucrose/aspartate $[1800 \mathrm{EU}(\mathrm{mg}$ protein $)^{-1}$ ] cultures and suggest that this enzyme is only partially derepressed in aerobic sucrose $/ \mathrm{NO}_{3}^{-}$medium. It is noteworthy that although glutamine synthetase and urease are co-regulated under most conditions (Friedrich \& Magasanik, 1977) such co-regulation was absent in both aerobic and anaerobic sucrose $/ \mathrm{NO}_{3}^{-}$cultures and urease was fully derepressed in both culture media (Table 2). 
We thank T. Punnett for his stimulating and helpful discussions. This work was supported by grant PCM 79-22122 from the National Science Foundation.

\section{REFERENCES}

AmerishinghaM, C. J. \& Davis, B. (1965). Regulation of $\alpha$-ketoglutarate dehydrogenase formation in Escherichia coli. Journal of Biological Chemistry 240, 3664-3667.

BachHuber, M. W., BRILl, W. J. \& Howe, M. M. (1976). Use of bacteriophage $\mathrm{Mu}$ to isolate deletions in the his-nif region of Klebsiella pneumoniae. Journal of Bacteriology 128, 749-753.

Cameron, J., Panasenko, S. M., Lehman, 1. R. \& DAvis, R. W. (1975). In vitro construction of the bacteriophage lambda carrying segments of the Escherichia coli chromosome, selection of hybrids containing the gene for DNA ligase. Proceedings of the National Academy of Sciences of the United States of America 72, 3416-3420.

Casadaban, M. J. \& Cohen, S. N. (1979). Lactose genes fused to exogenous promoters in one step using a $\mathrm{Mu}$-lac bacteriophage; in vivo probe for transcriptional control sequences. Proceedings of the National Academy of Sciences of the United States of America 76, 4530-4533.

Cohn, M. \& Horibata, K. (1959). Physiology of the inhibition by glucose of the induced synthesis of the $\beta$-galactosidase enzyme system of Escherichia coli. Journal of Bacteriology 78, 624-635.

Dobrogosz, W. J. (1966). Altered end-product patterns and catabolite repression in Escherichia coli. Journal of Bacteriology 91, 2263-2269.

Friedrich, B. \& MagasaniK, B. (1977). Urease of Klebsiella aerogenes; control of its synthesis by glutamine synthetase. Journal of Bacteriology 131, $446-452$.

Givot, I. L., Smith, T. A. \& Abeles, R. H. (1969). Studies on the mechanism of action of the structure of the nucleophilic center of histidine ammonia lyase. Journal of Biological Chemistry 244, 6341-6353.

Goldberg, R. B. \& Hanau, R. (1979). Relation between the adenylylation state of glutamine synthetase and the expression of other genes involved in nitrogen metabolism. Journal of Bacteriology 137, 1282-1289.

Goldberg, R. B. \& HanaU, R. (1980). Regulation of Klebsiella pneumoniae hut operons by oxygen. Journal of Bacteriology 141, 745-750.

GoldberG, R. B. \& Magasanik, B. (1975). Gene order of the histidine utilization (hut) operons in Klebsiella aerogenes. Journal of Bacteriology 122, 1025-1031.

Gray, C. J., Wimpenny, J. W. T. \& Mossman, M. R.
(1966). Regulation of metabolism in facultative bacteria. II. Effects of aerobiosis, anaerobiosis, and nutrition on the formation of Krebs cycle enzymes in Escherichia coli. Biochimica et biophysica acta 117, 33-41.

HadDock, B. A. \& Jones, C. W. (1977). Bacterial respiration. Bacteriological Reviews 41, 47-49.

HARRISON, D. E. F. (1976). The regulation of respiration rate in growing bacteria. Advances in Microbial Physiology 14, 243-314.

Kistler, W. S. \& LiN, E. C. C. (1971). Anaerobic L-glycerophosphate dehydrogenase of Escherichia coli: its genetic locus and physiological role. Journal of Bacteriology 108, 1224-1234.

Lessie, T. G. \& NeIDHARDT, F. C. (1967). Formation and operation of the histidine-degrading pathway in Pseudomonas aeruginosa. Journal of Bacteriology 93, $1800-1810$.

NeidhaRdT, F. C. \& Magasanik, B. (1957). Reversal of the glucose inhibition of histidase biosynthesis in Aerobacter aerogenes. Journal of Bacteriology $\mathbf{7 3}$, 253-260.

Prival, M. J. \& MagasaniK, B. (1971). Resistance to catabolite repression of histidase and proline oxidase during nitrogen limited growth of Klebsiella aerogenes. Journal of Biological Chemistry 246, 6288-6396.

Prival, M., Brenchley, J. E. \& Magasanik, B. (1973). Glutamine synthetase and the regulation of histidase formation in Klebsiella aerogenes. Journal of Biological Chemistry 248, 4334-4344.

Schlesinger, S., Scotto, P. \& Magasanik, B. (1965). Exogenous and endogenous induction of the histidine degrading enzymes in Aerobacter aerogenes. Journal of Biological Chemistry 240, 4331-4337.

Smith, G. R. \& Magasanik, B. (1971). The two operons of the histidine utilization system in Salmonella typhimurium. Journal of Biological Chemistry 246, 3330-3341.

Smith, G. R., Halpern, Y. S. \& Magasanik, B. (1971). Genetic and metabolic control of the enzymes responsible for histidine degradation in Salmonella typhimurium. Journal of Biological Chemistry 246, 3320-3329.

SPENCER, M. E. \& Guest, J. R. (1973). Isolation and properties of fumarate reductase mutants of Escherichia coli. Journal of Bacteriology 114, $563-570$. 